\title{
Participating in sports and practicing a religion are related to levels of happiness
}

Authors' contribution:

A) conception and design of the study

B) acquisition of data

C) analysis and interpretation of data

D) manuscript preparation

E) obtaining funding

\author{
Carlos Ma Tejero-González
}

Autonomous University of Madrid, Spain

\section{KEYWORDS}

\begin{abstract}
The objective of this study was to ascertain whether happiness varies depending on sports participation and religious practice. The sample comprised 2,378 participants aged between 18 and 92 years. All analysis were carried out by testing the interaction effects of the variables of sex and age on sports participation, religious practice, and happiness. We found a high average level of happiness $(M=7.299$, range $0-10)$. However, people who do not participate in sports or practice a religion indicated a level of happiness $(M=6.979)$ that was statistically lower than that of the other groups: people who practice a religion but do not participate in sports $(M=7.135)$; people who participate in sports but do not practice a religion $(M=7.478)$; and people who both participate in sports and practice a religion $(M=7.717)$. We conclude that happiness is associated with sports participation and religious practice, although with small or very small effect sizes (all $p<0.050 ; \eta^{2}$ between 0.008 and 0.020 ).

Social science applied to sport, spirituality, well-being.
\end{abstract}

\section{Introduction}

Happiness has been an object of reflection since at least the origins of philosophy in ancient Greece, and it is a classic theme of inspiration for music, painting, poetry, and art in general (McMahon, 2006). At present, happiness is the object of an exponentially increasing body of scientific study, though a great difficulty that emerges when studying happiness from a scientific perspective is the variation in its meaning across historical contexts and cultures (Oishi, Graham, Kesebir \& Galinha, 2013). In any case, it is known that 40 percent of the variance of happiness is associated with factors related to people's will and learning; some researchers interpret this finding as representing an opportunity for people to be happier through an awareness of suitable strategies (Lyubomirsky, 2008).

The exercise and sports sciences have also taken an interest in research into happiness, and there are several studies that have shown the association between happiness and sports participation (Balish, Conacher \& Dithurbide, 2016; Downward \& Rasciute, 2011; Huang \& Humphreys, 2012). At the same time, disciplines other than the sport sciences have also demonstrated that there exists an association between happiness and religious practice (Abdel-Khalek, 2006; Rizvi \& Hossain, 2017; Tay, Li, Myers \& Diener, 2014), though some studies question the consistency of this association (Lewis \& Cruise, 2006). 
In addition, several authors have postulated that although sports and religiosity are different forms of human expression, they share common elements - for example, the existence of group identity, flow, the presence of rituals and mythology, a commitment to improvement, collective practice, and social gathering (Deardorff, White \& Smith, 2008; Hoffman, 2010; Magdalinski \& Chandler, 2002; Parry, 2007; Parry, Nesti \& Watson 2011; Roychowdhury, 2019; Watson \& Parker, 2014). It therefore seems reasonable to design a study that addresses the association between happiness, sports participation and religious practice, on both separate and combined bases.

The objective of this study was to ascertain whether the happiness that people feel varies depending on whether they participate in sports, practice a religion, pursue both activities, or do neither.

\section{Methodology}

\section{Sample size}

This research analyzed the results of a survey (study number 3,029) conducted by the Spanish Centre for Sociological Research (Centro de Investigaciones Sociológicas, CIS). This survey was selected because it is the only one carried out by the CIS that contains questions about sports participation, religious practice, and happiness. A total of 2,485 face-to-face interviews were conducted in participants' homes. According to the technical details of the survey, the sampling error was 2\% (assumption of simple random sampling and confidence level of 95.5\%). For the purposes of the present study, we selected sampling units with complete data for all the variables mentioned in the following section. The final sample contained a total of 2,378 people, all of them residing in Spain (European Union); their ages ranged from 18 to 92 years. The CIS provided and authorized the use of the data for the present study.

\section{Variables}

Six variables were analyzed:

1) Sex: male; female.

2) Age in years: $18-30 ; 31-50 ; 51-70 ; 71$ or over.

3) Sports participation: does not participate in sports; participates in sports.

4) Religious practice: does not practice a religion (non-believers, atheists, or believers who almost never attend mass or religious services); practices a religion (Catholics or believers of another religion who attend religious services several times a year or more).

5) Combined variable of sports participation and religious practice: neither participates in sports nor practices a religion; practices a religion but does not participate in sports; participates in sports but does not practice a religion; participates in sports and practices a religion.

6) Happiness: Likert-type scale in which 0 is "completely unhappy" and 10 is "completely happy."

\section{Statistical analysis}

We deployed frequency analysis $(N)$, percentages $(\%)$, arithmetic means $(M)$, standard deviations $(S D)$, Chisquared $\left(\chi^{2}\right)$ tests, T test for independent samples $(T)$, and an ANOVA $(F)$ to examine the data. To analyze the relationships between happiness and sports participation and religious practice, we first used point biserial correlation $\left(r_{b p}\right)$ and then ANCOVA, comparing the main effects with Bonferroni adjustment and testing the interaction effects of the variables of sex and age on the rest of the variables. When statistically significant differences were found, we estimated the effect size via the partial eta-squared parameter $\left(\eta_{p}^{2}\right)$, using the following cut-off points: small effect (0.010), medium effect (0.060), large effect (0.160). Calculations were 
carried out with the help of SPSS version 25 (IBM Corporation, USA). The confidence level established was $95 \%(p<0.050)$.

\section{Results}

Table 1 contains the data on sports participation, religious practice, and happiness. In terms of sports participation, the percentage of men who participate in sports (48\%) is greater than the percentage of women who do so $(32 \%)$, and the percentage of the population that participates in sports decreases with age (18-30= $61 \% ; 31-50=47 \% ; 51-70=29 \% ; 71$ or over $=12 \%$ ). Regarding religious practice, the percentage of women who practice a religion (36\%) is greater than the percentage of men who do so $(22 \%)$, and the percentage of people who practice a religion increases with age $(18-30=16 \% ; 31-50=21 \% ; 51-70=36 \% ; 71$ or over $=$ $56 \%$ ). As for happiness, both men and women reported high and statistically equal levels of happiness (7.275 and 7.185, respectively), and it can be observed that although happiness remains at high levels for all ages, it decreases with age $(18-30=7.624 ; 31-50=7.259 ; 51-70=7.079 ; 71$ or over $=6.920)$.

Table 1. Descriptive statistics for sports participation, religious practice, and happiness

\begin{tabular}{|c|c|c|c|c|c|c|c|c|c|c|}
\hline \multirow[b]{2}{*}{ Variables } & \multirow[b]{2}{*}{$N$} & \multicolumn{3}{|c|}{ Sports participation } & \multicolumn{3}{|c|}{ Religious practice } & \multicolumn{3}{|c|}{ Happiness } \\
\hline & & $\begin{array}{c}\text { No } \\
\%\end{array}$ & $\begin{array}{c}\text { Yes } \\
\%\end{array}$ & $p$ & $\begin{array}{c}\text { No } \\
\%\end{array}$ & $\begin{array}{c}\text { Yes } \\
\%\end{array}$ & $p$ & $M$ & $S D$ & $p$ \\
\hline \multicolumn{11}{|l|}{ Sex } \\
\hline Male & 1.157 & 52 & 48 & $<0.001$ & 78 & 22 & $<0.001$ & 7.275 & 1.806 & 0.204 \\
\hline Female & 1.221 & 68 & 32 & $\left(\chi^{2}\right)$ & 64 & 36 & $\left(\chi^{2}\right)$ & 7.185 & 1.825 & $(T)$ \\
\hline \multicolumn{11}{|c|}{ Age (years) } \\
\hline $18-30$ & 429 & 39 & 61 & & 83 & 16 & & 7.624 & 1.622 & \\
\hline $31-50$ & 945 & 53 & 47 & $<0.001$ & 79 & 21 & $<0.001$ & 7.259 & 1.821 & $<0.001$ \\
\hline $51-70$ & 701 & 71 & 29 & $\left(\chi^{2}\right)$ & 64 & 36 & $\left(\chi^{2}\right)$ & 7.079 & 1.811 & $(F)$ \\
\hline$>71$ & 303 & 88 & 12 & & 44 & 56 & & 6.920 & 1.972 & \\
\hline
\end{tabular}

Note: $p=$ probability value for statistical significance, $\chi^{2}=$ Chi-squared test, $T=\mathrm{T}$ test for independent samples, $F=$ ANOVA.

Source: own study.

Table 2 shows the relationship between sports participation, religious practice, and happiness. A positive but weak association between sports participation and happiness can be observed for both men $\left(r_{p b}=0.134\right)$ and women $\left(r_{p b}=0.128\right)$. We also observed a positive association between religious practice and happiness, but only in the case of men, and the association was very weak $\left(r_{p b}=0.084\right)$.

Table 2 Correlation between sports participation, religious practice, and happiness

\begin{tabular}{lcccc}
\hline & \multicolumn{2}{c}{$\begin{array}{c}\text { Sports participation } \\
(\mathbf{n o}=\mathbf{0}, \text { yes }=\mathbf{1})\end{array}$} & \multicolumn{2}{c}{$\begin{array}{c}\text { Religious practice } \\
(\mathbf{n o}=\mathbf{0}, \text { yes }=\mathbf{1})\end{array}$} \\
\hline $\begin{array}{l}\text { Happiness } \\
(0-10 \text { scale })\end{array}$ & Men & Women & Men & Women \\
\hline
\end{tabular}

Note: The point biserial correlation coefficients are shown in the cells. $* *<0.010$.

Source: own study.

Table 3 presents the results on happiness according to sports participation and religious practice. There was a high level of happiness for the total sample $(M=7.229)$. By conducting an ANCOVA, and having tested the interaction effects of the variables of sex and age on the variable of sports participation, we observed that there was a greater level of happiness among people who participate in sports $(M=7.528)$ compared to those who do $\operatorname{not}(M=7.033)$, with a small effect size $\left(F=22.85, d f=3, p<0.001, \eta^{2}=0.010\right)$. Regarding religious practice, 
we found a higher level of happiness among those who practice a religion $(M=7.300)$ compared to those who $\operatorname{do} \operatorname{not}(M=7.200)$, with a very small effect size $\left(F=11.35, d f=1, p=0.001, \eta^{2}{ }_{p}=0.005\right)$. In the same vein, in terms of the combined variable of sports participation and religious practice, statistically significant differences were also found, with a small effect size $\left(F=11.90, d f=3, p<0.001, \eta^{2}{ }^{2}=0.015\right)$.

Table 3. Association between sports participation, religious practice, and happiness

\begin{tabular}{|c|c|c|c|c|}
\hline \multirow{2}{*}{ Variables } & \multicolumn{2}{|c|}{ Happiness } & \multirow[b]{2}{*}{$\boldsymbol{P}$} & \multirow[b]{2}{*}{$\eta_{p}^{2}$} \\
\hline & $M$ & $S D$ & & \\
\hline Sample total & 7.229 & 1.815 & - & - \\
\hline \multicolumn{5}{|l|}{ Sports participation } \\
\hline No & 7.033 & 1.947 & \multirow{2}{*}{$<0.001$} & \multirow{2}{*}{0.010} \\
\hline Yes & 7.528 & 1.547 & & \\
\hline \multicolumn{5}{|l|}{ Religious practice } \\
\hline No & 7.200 & 1.795 & \multirow{2}{*}{0.001} & \multirow{2}{*}{0.005} \\
\hline Yes & 7.300 & 1.864 & & \\
\hline \multicolumn{5}{|l|}{ Sports participation and religious practice } \\
\hline Neither participates in sports nor practices a religion & 6.979 & 1.940 & \multirow{4}{*}{$<0.001$} & \multirow{4}{*}{0.015} \\
\hline Practices a religion but does not participate in sports & 7.135 & 1.957 & & \\
\hline Participates in sports but does not practice a religion & 7.478 & 1.549 & & \\
\hline Participates in sports and practices a religion & 7.717 & 1.532 & & \\
\hline
\end{tabular}

Note: $M=$ arithmetic mean, $S D=$ standard deviation, $P=$ probability of statistical significance, $\eta^{2}{ }_{p}=$ partial eta-squared effect size. ANCOVA with adjustment for the variables of sex and age.

Source: own study.

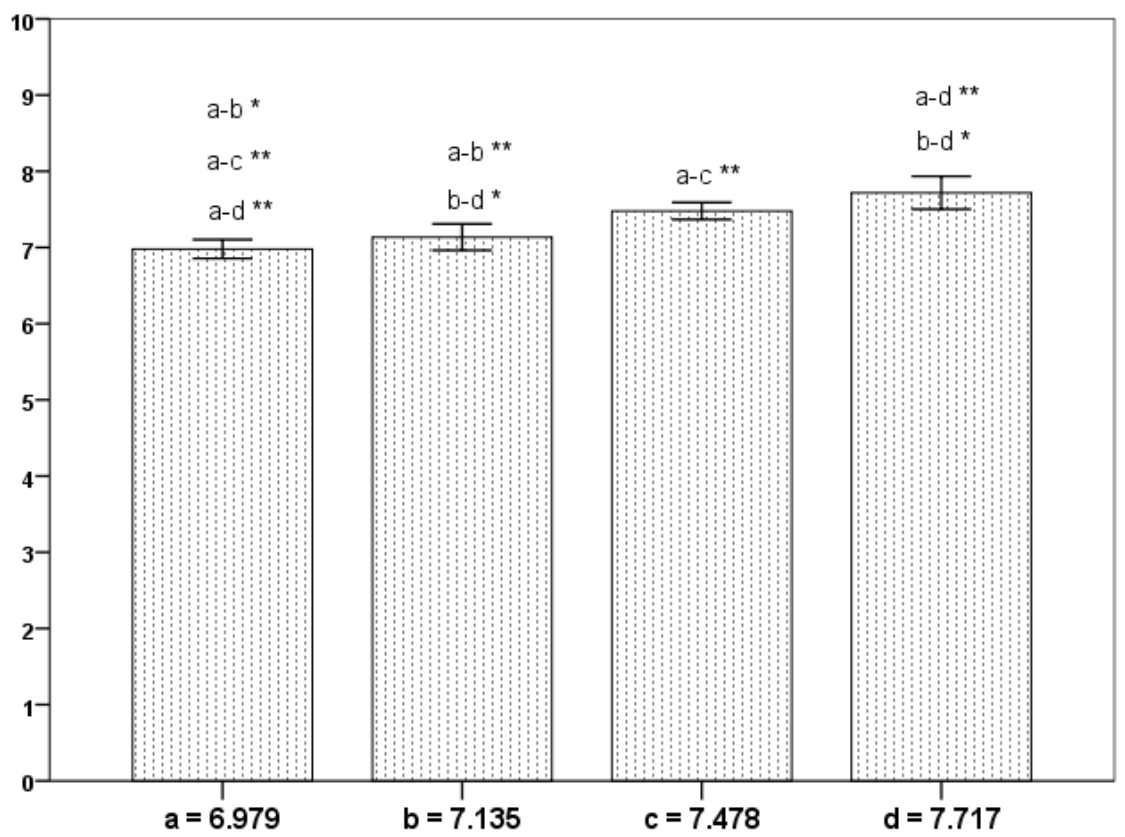

Figure 1. Bar chart of the relationship between happiness and the various groups for combinations of sports participation and religious practice

Notes: appearing next to $\mathrm{a}, \mathrm{b}, \mathrm{c}$, and $\mathrm{d}$ is the arithmetic mean for happiness corresponding to the different groups: a $=$ the group that neither participates in sports nor practices a religion; $b=$ the group that practices a religion but does not participate in sports; $\mathrm{c}=$ the group that participates in sports but does not practice a religion; $\mathrm{d}=$ the group that participates in sports and practices a religion. Symbols: * probability of statistical significance $<0.050$; ** probability of statistical significance $<0.010$; error bars represent confidence intervals at 95\%. ANCOVA with adjustment for the variables of sex and age.

Source: own study. 


\section{Discussion and conclusions}

The study was designed with the aim of ascertaining whether happiness varies depending on sports participation, religious practice, or both practices together. Our main conclusion is that happiness increases with sports participation and religious practice, both separately and in combination. However, it must be borne in mind that the association between happiness and sports participation corresponds to a small effect size, and that between happiness and religious practice to a very small effect size.

In any case, it can be observed that the cohort that neither participates in sports nor practices a religion indicated a lower level of happiness than did the rest of the cohorts. By the same token, people who participate in sports and practice a religion declared the highest happiness levels, though there is no statistically significant difference between this group and the group that participates in sports but does not practice a religion, which shows that the relationship between happiness and sports participation is stronger than the relationship between happiness and religious practice. This result is similar to the findings of Balish, Conacher, and Dithurbide (2016), who state that the association between happiness and being an active member of a sports or leisure organization (OR $=1.38)$ is greater than the association between happiness and being a member of a religion $(O R=1.26)$.

One possible strength of this study is in its use of the only CIS survey that includes questions about sports participation, religious practice, and happiness. This is a positive attribute because, in addition to the fact that the CIS study contains information on the three variables, said study benefits from the methodological rigor and the quality of CIS surveys, in terms of both sample size and the data-collection procedure used, namely a survey administered via face-to-face interviews. However, we must point out that although the survey-based design makes it possible to identify associations, it does not allow causal conclusions to be drawn. So, this paper shows correlations that they are not enough to imply causality.

Moreover, although the data from this study are valid, they must be treated with caution due to the limited reliability of the measurements of the different variables. For example, rather than measuring sports participation in a basic and dichotomous way, it would be desirable to measure physical activity and sports (Dishman, Washburn \& Schoeller 2001). Likewise, a more comprehensive instrument that discriminates between spirituality and religiosity could be used (King \& Crowther 2004), and happiness could be measured with an instrument that involves more than a single question (Helm, 2000).

In view of the results obtained, and despite the limitations set forth above, a question arises: Why are sports participation and religious practice associated with greater happiness, even though the effect size is small or very small? The literature that takes happiness as its scientific object allows us to affirm that happiness is positively associated with social relations and the feeling of belonging to a group (Lyubomirsky, 2008); both sports participation and religious practice are conducive to this social facilitation of happiness (Balish, Conacher \&Dithurbide, 2016). Furthermore, happiness is also positively associated with perceptions of physical wellbeing and self-esteem (Lyubomirsky, 2008), and thus it is possible that this is the value of sports participation.

In any case, future research should analyze variables that this study did not. For example: there are many kinds of sports, many different approaches to practicing sports (how often and how intense, individual or group sports, etc.) and many different kinds of religions (with different teaching, morality, etc.) and with different approaches to practicing it (ceremonies, collective prayer, individual meditation, social activities and so on). Besides, sports participation and religion practice are two activities of engagement but there are other factors belonging to commitment experiences, such as: membership in clubs, involvement in hobbies, participation in service organizations, that they may be factors correlate with happiness. Needless to say, this very study could (ought to?) be replicated with recent data and adding new variables. 


\section{Ethics approval and informed consent}

The study was approved by the Research Ethics Committee of the Autonomous University of Madrid (CEI 48915).

\section{Competing interests}

There is no conflict of interest in this study.

\section{Funding}

The author declares this study was carried out without funding nor financial support.

\section{Acknowledgments}

This study was made possible by the Spanish Centre for Sociological Research. As well, the author would like to express its gratitude to the reviewers of Physical Culture and Sport. Studies and Research, who have contributed to improve the paper with their comments during the review process.

\section{REFERENCES}

Abdel-Khalek, A. (2006). Happiness, health, and religiosity: Significant relations. Mental Health, Religion \& Culture, 9(1), 85-97. DOI: https://doi.org/10.1080/13694670500040625

Balish, S. M., Conacher, D., \& Dithurbide, L. (2016). Sport and recreation are associated with happiness across countries. Research Quarterly for Exercise and Sport, 87(4), 382-388. DOI: https://doi.org/10.1080/02701367.2016.1229863

Deardorff II, D., White, J., \& Smith, J. K. A. (2008). The image of god in the human body: Essays on christianity and sports. Lampeter: The Edwin Mellen Press Lewiston.

Dishman, R. K., Washburn, R. A., \& Schoeller, D. A. (2001). Measurement of physical activity. Quest, 53(3), 295-309. DOI: https://doi.org/10.1080/00336297.2001.10491746

Downward, P., \& Rasciute, S. (2011). Does sport make you happy? An analysis of the well-being derived from sports participation. International Review of Applied Economics, 25(3), 331-348. $\quad$ DOI: https://doi.org/10.1080/02692171.2010.511168

Helm, D. (2000). The measurement of happiness. American Journal on Mental Retardation, 105(5), 326-335.

Hoffman, S. J. (2010). Good game: Christianity and the culture of sports. Waco: Waco Baylor University Press.

Huang, H., \& Humphreys, B. R. (2012). Sports participation and happiness: Evidence from US microdata. Journal of Economic Psychology, 33(4), 776-793. DOI: https://doi.org/10.1016/j.joep.2012.02.007

King, J. E., \& Crowther, M. R. (2004). The measurement of religiosity and spirituality. Journal of Organizational Change Management, 17(1), 83-101. DOI: https://doi.org/10.1108/09534810410511314

Lewis, C. A., \& Cruise, S. M. (2006). Religion and happiness: Consensus, contradictions, comments and concerns. Mental Health, Religion \& Culture, 9(3), 213-225. DOI: https://doi.org/10.1080/13694670600615276

Lyubomirsky, S. (2008). The how of happiness: A scientific approach to getting the life you want. New York: Penguin Press.

Magdalinski, T., \& Chandler, T. J. L. (2002). With god on their side: Sport in the service of religion. London New York: London New York Routledge.

McMahon, D. M. (2006). Happiness: A history. New York, US: Atlantic Monthly Press.

Oishi, S., Graham, J., Kesebir, S., \& Galinha, I. C. (2013). Concepts of happiness across time and cultures. Personality and Social Psychology Bulletin, 39(5), 559-577. DOI: https://doi.org/10.1177/0146167213480042 
Parry, S. J. (2007). Sport and spirituality: An introduction. London New York: London New York Routledge.

Parry, S. J., Nesti, M., \& Watson, N. (2011). Theology, ethics and transcendence in sports. New York: New York Routledge.

Rizvi, M., \& Hossain, M. (2017). Relationship between religious belief and happiness: A systematic literature review. Journal of Religion and Health, 56(5), 1561-1582. DOI: https://oi.org/10.1007/s10943-016-0332-6

Roychowdhury, D. (2019). Spiritual well-being in sport and exercise psychology. SAGE Open, 9(1). DOI: https://doi.org/10.1177/2158244019837460

Tay, L., Li, M., David Myers, D., \& Diener, E. (2014). Religiosity and Subjective Well-Being: An International Perspective. In C Kim-Prieto, Religion and spirituality across cultures (pp. 163-175). Dordrecht: Springer Netherlands.

Watson, N. J., \& Parker A. (2014) Sport and the Christian religion: A systematic review of literature. Newcastle: Newcastle Cambridge Scholars Publishing.

\section{AUTHOR'S ADDRESS:}

Carlos $\mathrm{M}^{\mathrm{a}}$ Tejero-González

Autonomous University of Madrid

Faculty of Teacher Training and Education

Street: Fco. Tomás y Valiente, 3. Campus Cantoblanco

28049 Madrid, Spain

E-mail: carlos.tejero@uam.es

Received: 22 January 2020; Accepted: 1 April 2020 